\title{
Five Cardinal Questions on Administrative Psychiatry.*
}

\section{By J. Mundy, M.D.}

“ Non progredi est regredi."

WE have in two previously published papers ${ }^{2}$ promised to discuss the following questions, and now attempt to fulfil the promise in the following pages. The questions are :

1. What false ideas are still prevalent among the public at large in relation to lunatic asylums and their superintendents and psychological physicians in general?

2. Are the mode and description of state supervision and control, as exercised over asylums, sufficient and satisfactory?

3. To what persons, and under what conditions, shall the privilege be exclusively conceded to establish, superintend, and carry on establishments for the insane?

4. Ought lunatic asylums to be entrusted to religious corporations?

5. May not families of position and competency be lawfully permitted to retain the charge and management of their mentally afflicted relatives, under the "patronal or family régime"?

I. The first question renders it necessary for us at the outset to fix the signification and precise meaning of the phrase "public at large," so as to obviate any misconception.

* It is right to state that the learned anthor of this paper has, with one or two exceptions, visited the asylums of every country on the continent of Europe, and that it is the intention of the following pages to convey the result of his impressions on those asylums. Dr. Mundy has now commenced an investigation into the state of our own asylums, and we trust that he will be able to pass a more favorable judgment upon us than he has done upon our continental fellow-labourers; hut we must expect severe criticism from one who is opposed to the asylum system generally, and is a zealous advocate of the Gheel system at large. The maxim, however, is sound-" fas est ab hoste doceri."

"Rien n'est si dangereux qu'un ignorant ami ; Mieux vaudrait un sage ennemi." $-[\mathrm{ED}$.

+ See in the 'Journal de Médecine de Bruxelles,' 1860, the article "La folie du suicide et le suicide du Comte Etienne Szchenyi," p. 193, and in connexion with Question IV, the 'Correspondenz-Blatt,' 1860, p. 303. 


\section{Five Cardinal Questions on Administrative Psychiatry,}

In the questions advanced, we divide the public into the wealthy educated, and the poor who have had no extended instruction or education; of the lower classes or the masses we do not speak at gll. If we now examine the opinions and views of the so-called educated class, first, in relation to the administration of lunatic asylums; then with reference to the superintendents or directors of such institutions; and, lastly, with regard to physicians specially engaged with the insane, we shall arrive at the following results :

Of the condition of the insane in past centuries, till within the short space of about twenty years, next to nothing is known, even by the educated public. The reason of this is to be found in the fact that the writers of history have never put themselves to the trouble of describing in ever so few words the barbarities of those bygone times, the dreary episode of human brutality and ignorance. Records of this special department of knowledge have only existed during the last few years, and their details have always been meagre. Men seemed to be ashamed of the past, and to regard with terror, not altogether unreasonable, the disclosures of the present, and it was a few high priests of our science, who, with self-sacrificing courage, tore aside the veil from the disgraceful picture.

Wherefore the names of Daguin, Pinel, Esquirol, Brierre de Boismont, Moreau de Tours, Willis, Hill, Conolly, Schröder van der Kolk, Guislain, Parigot, Langermann, Roller, Damerow, \&c., should be regarded as the fixed stars lighting up the still very clouded firmament of our science.

But who knows aught of the above-cited or of many other benefactors of mankind who emulate them, except perhaps their names, beyond the narrow circle of specialists, or the still more restricted circle of fellow-countrymen or fellow-citizens.

Yes, alas! it must be confessed that men of this sort, hallowing only the place in which they work, avoid the pompous glitter of pub. licity. Wherefore it mostly happens that even the educated man only becomes acquainted with them when he, or some friend or relative, has been smitten with the greatest of human ills. Yet scarcely has such a patient recovered when he, or if he dies, his friends or acquaintances, forget only too soon the great and self-sacrificing toil endured often through many years of solicitude and care by the physician, whose name soon almost vanishes from memory. Respecting the last twenty years we must speak more at large, and will represent the opinion of the public in the following words :- "It cannot be denied," says the educated man, "that in bygone ages the insane were very much neglected, and frequently inhumanly treated; but in modern times this state of things is entirely changed."

On perceiving in the vicinity of a capital or provincial town, in any country, a stately building, which lies apart from the streets, 
presenting peculiarities in form and construction, and surrounded by extensive and beautiful grounds, the observer may be well nigh certain, on putting the set question, "What fine building is that?" to receive the answer, "It is a lunatic asylum." After receiving the above reply, the observer will notice the walls, of greater or less height, which inclose the whole establishment, and give the necessary security.

Should he receive permission to inspect this palatial charitable institution, - and the permission is readily and courteously accorded by the director, he will be perfectly satisfied, and have his misgivings removed respecting the care and treatment which the insane now-adays enjoy. Indeed, in this matter, humanity has advanced with the advancing knowledge of the subject. Even the arohitectural details exhibit taste and constructive skill, and very often display an unusual luxury.

The approach to such a building is through a beautiful portico, doors and entrances, adorned with columns, and artistically wrought gates; and we are next ushered in by the polite porter into a tastefully furnished waiting-room, where, in the company of books and journals, we wait by the comfortable fire-side for permission to make a farther inspection of the asylum.

If it be a public institution, or one maintained by the State, it is mostly of very considerable extent, and its director, physician, or other officer, can seldom, indeed, on account of the loss of time, personally accompany us in our visit; but if it be a private asylum, the manager or proprietor will, in most cases, courteously act as our conductor. And, first of all, we pass by some side stairs into the well-ventilated and lighted corridors, adorned with pictures, and from the tasteful windows, protected by safe but not obtrusive gratings, we can mostly enjoy a beautiful prospect of the immediately surrounding neighbourhood. Opposite to, or running parallel with, the decorated corridor, we find a number of rooms, which differ in no respect from our usual dwelling-rooms, and contain everything in any way conducive to comfort. In these apartments, neither flowers nor books are wanting; a cage, with its feathered inhabitants, cushioned couches and divans, mirrors, rich curtains, candelabra, and clocks, with carpets of the most exquisite patterns, combine to make the ensemble of the sitting-room of a lunatic member of a rich family, in the well appointed public or private establishments of the present day. Moreover, we must not forget that the patient is not obliged to pass his whole time in this one room, for frequently he has several such, and a separate sleeping-room for his use; and indeed, in most cases, he is encouraged to pass his time and to amuse himself in the general drawing-, or reception-room, in the company of other quiet inmates, and of the director of the asylum 
and his family. This reception-room is usually handsomely decorated, and contains, besides a piano, with the newest musical publications, other instruments, and among them the harp; while adjoining it is a billiard-room, with every sort of appliance for other games, such as chess, backgammon, draughts, shuttle-cock, races, cards, dominos, puzzles, \&c. Indeed, every new game invented is sure to be procured for the asylum. Another apartment contains a rich and well-selected library, set apart for the use of the insane, and always freely open to them. But how much will the visitor be astonished to find a highly decorated ball-room and orchestra, which in large asylums are sometimes splendidly appointed,-where the unfortunate, or as he might be almost tempted to say,- " the lucky inmates" of both sexes enjoy themselves with music and dancing, with balls and concerts. T'o render a complete account he must also remark their liberty out of doors, and their participation in occupations, in intercouse, and in amusements, as well as in all other salutary and agreeable pastimes.

'The wealthy insane patient, who can appreciate such influences, will often enjoy in the company of the family of the physician of the asylum, or of the officers and attendants, excursions and drives, country parties, and visits into the town, and may even be not unfrequently allowed to attend the theatre or other place of amusement, when it is not likely to be prejudicial to his disorder.

The poor, like the rich, receive, without impediment, in the asylums, the visits of relatives, friends, and acquaintances.

The man of letters here occupies himself with his books, whenever so inclined; the politician, with the newest journals; the painter and sketcher, with brush, pencil, and pallette ; in short, each profession with its usual and favorite employment. In the same manner, the mechanics and labourers are furnished in the workshops belonging to the institution with opportunities to usefully employ themselves and divert their minds.

Hence it is that asylums are so constructed as to resemble small manufacturing towns, and have their special shops for smiths, locksmiths, turners, house-painters, upholsterers, cabinet-makers, bookbinders, \&c., and not unfrequently printers are found, who execute all the printing for the establishment; whilst brewers, bakers, butchers, and millers, carry on their several occupations in the particular departments allotted them, and supply the wants of the asylum. The agricultural labourers are employed in the fields and meadows belonging to the asylum, and the farm servants take care of the well-stocked cow-house, the horses, oxen, goats, pigs, sheep, and cows. The masons are employed in the repairs of the building, and instances happen where the chimney-sweep is one of the diseased inmates of the establishment. 
Nor must we forget the other sex, some of whom are engaged with the delicate work of ladies, such as embroidery, whilst others are occupied with the hard work of the washhouse, ironing and cleaning, and with the business of the kitchen, or with huusekeeping; whilst others, again, are industriously engaged in needle-work and knitting.

It is at once evident that all these occupations and amusements are not forced upon the patients, but are entirely the results of their own free will, and the disposition to them is looked upon as a lever to their restoration to health.

The economical value of such an organization to an asylum needs no words to elucidate it.

After viewing the regally fitted kitchens, where gas and steam take the place of fires, and the brewhouse, bakehouse, and larder, which are arranged on the newest principles, we proceed to view the model farming department, the fields and stables; nor must we omit to visit the store-rooms, well filled with linen and clothing, and with sugar, tea, and other articles of food; the newest contrivances for washing and drying, and, lastly, the steam-engine, the boilers, and the reservoirs, - in order that we may fairly arrive at the conclusion that all is here provided which it is possible at any time, under the circumstances, to desire.

We must say a word respecting the beautiful church or chapel, with its organ, which constitutes one of the ornaments of the institution; and of the schools, in which pains are taken to impart instruction, even to the poorest idiot, in religion, and in writing, reading, arithmetic, drawing, \&c. Having sufficiently indicated the presence of these things, we must proceed further in our walk through the building.

Adjoining the reception-room in the institution we usually find the dining-room, which, like all the other apartments in the house, is lofty, roomy, well-ventilated and lighted, and in winter well and judiciously warmed, and, in the evening, illuminated with gas. The table-linen is of very good quality, and so also the dinner-service; ingenious arrangements are contrived for raising the food to the different stories.

$\Lambda$ fter the short description already given of the kitchen, and of the entire domestic economy, no doubt will be felt with respect to the food and drink, that both its quantity and quality are superior. Three or even four meals are allowed every day; in the morning, between seven and eight, breakfast consisting of soup, or tea and coffee, with white and black bread and the best and freshest butter; dinner, between twelve and three o'clock of soup, vegetables, meat, or farinaceous food, often, also, fish, fruit or pastry, and sufficient bread; for drink, wine or beer; supper between six and eight 


\section{Five Cardinal Questions on Administrative Psychiatry,}

o'clock, of soup, tea, and some other article of food. In many asylums there is besides either a luncheon, or a slight afternoon repast, according as the meals are divided. Extras are also allowed those who are sick, and on festive occasions.

Consideration must necessarily be given in such matters to the circumstances and customs of different countries and people, and the usage be regulated accordingly.

Between seven and eight o'clock in the evening, all the inmates of the asylum retire to rest. For the more delicate and wealthy patients, the separate sleeping rooms are in winter well warmed, the beds are broad and well supplied with bedclothes; for the poorer classes, the common sleeping rooms and dormitories are spacious, and also well warmed, and the beds and bedding ample. In these dormitories which have night-lights, properly protected, vigilant attendants are always on the watch, ready to attend to the wants of those entrusted to their charge. For the nightly quiet and security of the asylum, there is a night-watch, sufficiently numerous, both within and without the building.

Those insane whose condition forbids their association with others, are placed in special rooms and cells, and tended with still greater attention and care. Since such a cell, when occupied, is not an agreeable sight, instead of opening it, another, without an inmate, will serve our purpose of inspection, and we observe it to be softly padded throughout, and arranged in a very practical way, and its aspect leads us to conclude that the dangerous patients are comfortably lodged and well cared for.

We have yet to mention the several courts, which are mostly laid out as gardens, and afterwards, the large and beautiful gardens, or rather parks of the establishment, where there are places set apart for skittles and gymnastics.

The establishment is moreover provided with warm and cold baths and douche apparatus, with water-closets of the best construction, and lastly with a well-appointed dispensary. The professional staff, and that of male and female attendants, and all the officials of the asylum, are above all praise.

Some officially accredited inspectors, and a Committee of Visitors exercise a frequent supervision, mostly unexpectedly, over all the affairs of the asylum, give their sanction to the Reports, and transmit them to the Ministers of State.

On quitting the asylum we shall pass by its principal wide staircase, and be courteously invited by our conductor to enter our names, and any casual observations we would make in the register prepared for that purpose.

We thereupon leave this establishment, which on the first sight of it induced us to inspect it, and which truly deserves to be called an 
asylum for the unfortunate insane. We find quiet and order reigning where we had feared discordant wailings and confusion; gentle and judicious arrangements and comfort, often, in fact, luxury and elegance, where we presupposed restriction and wretchedness ; extreme cleanliness, where we expected the contrary in its highest degree ; agreeable diversions and amusements, where we had reason to expect only force and restraint ; and instead of roughness and dull indifference, we find the most indefatigable, affectionate, and sympathising treatment of the insane.

The strictest control on the part of the superior authorities, the assiduous chronicling of everything that can be of interest to the public at large, to science, and to art, at the present and in future time, that completes the picture of our impressions which we may sum up in the following words: "truly in our century the utmost endeavours have been made to cure the insane, and to make the lot of the incurable as agreeable as possible."

Who, after reading the above account, does not feel called upon to render thanks to the legislators and promoters of such humane institutions, and also to the superintendents, officers, and physicians, of asylums, who have herein certainly done the most valuable service. It only remains for us to remark, that the insane themselves whom we have seen, almost without exception, seemed contented and pleased, were exceedingly well fed, and gave the most ready answers to our questions ; indeed the majority of them declared themselves well contented with their lot. Praise was liberally bestowed on their attendants and physicians, and they spoke with affectionate regard of the Director of the Asylum. Such would be the general colour in which the educated classes might express themselves in recording their observations and opinions, after having inspected one of the larger or smaller of the so-called "Model Asylums of Europe."

We might, however, look to meet with individuals, who, after repeated visits to their relatives, the unfortunate inmates of lunatic asylums, would give less favorable accounts of their treatment and care, but the number of these is very small ; some others, indeed, are met with who make loud complaints of violence, restriction, selfishness of greed, and neglect of their friends confined in asylums, and ridicule the impotence and inefficiency of the system of treatment of the insane, and its apostles.

First among the latter must be reckoned those general malcontents, who daily quarrel with the sun, and earth, and the water, air, and heat; and next again a select few, who appropriate to their purpose any facts and data of science, as well as of experience, as proofs to substantiate their own morbid impressions. To this latter class only need any heed be given by us. But as we have here to treat of what is the general rule, we must keep to the opinions and judgment of 


\section{Five Cardinal Questions on Administrative Psychiatry,}

the great approving majority, who have been accustomed to represent the management of asylums at the present time to be not otherwise than we have stated.

Let us now endeavour without bias to examine the other side of this description, and in doing this it is our duty to carry on our observations in a more precise and professional manner. For this purpose we shall propound for solution the practical question:What is the actual condition and the arrangement of asylums at the present time?

To answer this comprehensive question thoroughly, is beyond the scope of a periodical, and one needs for it the space of a bulky volume.

This being premised, we shall escape the onus of duty which might be expected of us, and at the same time shall have recourse in the first place, to our independent views based upon our own long experience, and on the minute inspection of asylums, and in the next to the information obtainable from the highest authorities in this department of knowledge.

With this end in view, we have made it our duty to specially study the matter in most of the countries of Europe. Of those countries in the south and north of this continent, which we have not yet visited, and of those not in Europe, we have diligently studied the literature of our subject, and have taken the opportunity to correspond with many specialists of foreign countries, both by oral and written communications.

At present, however, we shall exclusively speak of Europe. And as we have above intimated, we can here make only a very limited use of all the materials in our possession, and are obliged to treat this essay throughout in an aphoristic manner.

We hope hereafler to be able in a systematic work, to go into detail respecting all the matters relating to the subject before us. (We are at present engaged upon such a work, and have put forward some of its leading topics in an essay on "Gheel, un Asile patronale," published in the 'Journal de Médecin,' Brussels, 1860, and later in a paper, in the 'Medical Critic, and Psychological Journal,' July, 1861, "On the Gheel Question.")

In no department of administrative psychiatry, do we find such utter contradictions and inconsequent reasoning, indeed, to an extreme degree, as exists in this one. It would be a satirical, or rather a tragi-comic proceeding, to take up one of the first and best annual volumes of our special journals, and to search for proofs of this fact, and to cite them in evidence. Here we light upon a brilliant encomium, to the effect that everything in administrative detail has been accomplished for the insane; and by the side of this a long-winded jeremiad, that as yet nothing has been accomplished in this direction. 
Where are we then to look for the golden medium ? A candid "Non possumus" is our only answer.

Our extended observations and experience, alas! lead us to the lamentable conclusion, that the present condition and organization of the asylums of Europe, are at large, and in general, unsatisfactory and bad.

Let no one venture to cite exceptions to us as counter-evidences; we know of these only too well, and speak here of what is the general rule; we must still more protest against any presumed exaggeration in the following descriptions; the more so as we have regarded it as our duty to speak very guardedly. If compelled, we must respond by giving data, which would be disagreeable both to ourselves and others. Propositions of reform we can do no more than allude to in passing, for such matters do not belong here, but are the subject of the great question of the day, which the radical reform of lunatic asylums has opened up for debate.

It is a generally adinitted fact, that there are in Europe about 250,000 insane persons. Taking this number in relation to the entire population of Europe, viz., 250,000,000, it appears that the proportion of the insane is as 1000 to $1,000,000$ souls ; but this ratio is doubtless much below the fact.

Indeed, the official reports of every country coincide in asserting that there are always many insane persons kept concealed with their families, and others indiscriminately scattered as harmless cases, both in town and country, without being officially registered as lunatics. A large number of idiots are referable to this class, and likewise nearly all cretins, whose number in some countries is very considerable.

We cannot by any means accept the official calculation of 250,000 insane in Europe, for in our opinion that statement is quite set aside by the fact, that in many countries the per-centage of the insane to the population is shown to be much higher than 1000 in the $1,000,000$, and we cannot go far wrong in assuming the round number of 300,000 insane. For these 300,000 lunatics in Europe, in the year 1861, there are, according to official data, 1000 asylums. This number does not comprehend all the institutions which bear the name of asylums, but only those where lunatics are received as a rule.

It would be a preposterous proceeding to take the entire insane population of 300,000 , and to divide it equally among the 1000 asylums, and therefrom deduce the statement that there are 300 inmates in each asylum. On this matter, no further proof is requisite. The special analysis of the foregoing figures is forbidden, not only by the limited space of these pages, but still more by the perpetual variation in the number of lunatics, and lastly, by the entire deficiency of data from many private asylums. 
352 Five Cardinal Questions on Administrative Psychiatry,

From all we know, this much may be received as completely established, that the number of asylums at the present time is entirely insufficient, and in every country of Europe, whilst we are preparing this paper, new asylums are in course of erection, or projected (see our remarks in the second of the two articles already quoted). The greatest impediment that presents itself to us, in the examination of the condition of lunatic asylums, is the mode of classification adopted in them. On this point, we must first reply to the questions :A. What is a model asylum? B. Are there any such? c. Which institution can be called good, and which indifferent or bad? D. Which of these classes is the most common? E. Which constitutes the exception? If we desired to proceed in detail, in replying to these queries, and to adduce the examples necessary as evidence, we should be involved by such a course in personalities, which it is our especial wish to avoid. Let us therefore assume these questions to be answered summarily, by the fact, that, with special reference to the professional direction and administration of an asylum, of which the first is the most important factor in our discussion, that that institution is pronounced by us and to be accounted good, in which-

1. 'The curable insane are restored, "cito et jucunde."

2. The lot of the incurable insane is rendered as agreeable as possible.

Where these two conditions are wilfully and knowingly omitted, or where, from ignorance or neglect, their fulfilment is impeded, we are compelled to reckon those institutions, according to the extent of the omissions, either among middling or bad asylums.

So-called model asylums, or particular models of asylums, do not, generally speaking, in our opinion exist; for on account of the peculiar relative institutions of different countries and people, and their requirements, very many modifications occur in their direction, and these even must be extended to the separate provinces of different states.

We must with pain confess that in the latter portion of the 19th century the charge is valid " that it must be allowed, as a rule, that the lunatic asylums of Europe, and their arrangements, are still in a very unsatisfactory condition, whilst the number of those suited to their purpose form only a small exception." it!"

This statement calls forth from every side the shrill cry, "Prove

This we will at once prove objectively (avoiding the subjective aspect of our inquiry). But for the sake of the clearness of our summary, and for the necessary condensation, we will put our proofs into the form of the following decisive questions to our opponents.

1. Is not the systematic, unrestricted and indiscriminate sequestration of all the insane, which is still held as an established prin- 
ciple, a piece of barbaric routine that must be broken through, and the more so inasmuch as this proposed change has been proved, scientifically and practically, both possible and necessary? Shall we not soon see that system come forth from Belgium's BethlehemEphratah's little town of Gheel-Campine, which shall be the saviour of the insane? or shall more than half of the 300,000 insane in Europe be for ever uselessly and ruthlessly shut up and restrained in places of seclusion?

2. Shall and must not the system of "non-restraint," as proved on the strongest evidence to be practically the best, both for the treatment and the management of the insane, be generally adopted for those who require continual seclusion? Shall the practical proof of this supplied to us in England, and so nobly asserted theoretically, and established practically, by the illustrious John Conolly, be treated with indifference?

Cannot the distressing sight of thousands of our fellow-creatures, intrusted to us to cherish and care for, fettered with strait-jackets, bound in chairs, or in beds, or in dark cells, with the various apparatus of restraint, induce us to completely cast away the whole system of coercion?

And what is it that hinders the largest number of our opponents from acknowledging the necessity of this reform and of its application?

We assert in plain words, that it is the power of custom, of indolence, of love of ease, and of ignorance of the new system, of unwillingness to accept the evidence and to undertake the study of it, and probably in many instances, of the want of opportunities to undertake such studies. And may we not accuse those who practise this barbaric routine of timidity and selfishness?

Indolence and ignorance keep the various governments from putting an end to the present practice by the force of law. With the public at large, of every class, indifference, egotism, and complete miscon. ception or ignorance of the existing state of things, concur to render it apathetic. There now remains but a small number of men who devote their time, money, and position to the defence of these principles, and who may consider themselves fortunate if they are not, on that account, themselves presumed to be insane, and in consequence secluded, imprisoned, and confined in strait-waistcoats.

But to proceed to our remaining queries :-

3 . Who can accuse us of exaggeration, or it may be falsehood when we assert, on the basis of our own researches, that :-

(a) Of the 1000 asylums existing in Europe, scarcely the half can be said to be adapted to their purpose, and even this proportion will only pass muster if we abstain from opposing the old system? 
(b) That it is a matter of fact, that the larger proportion of the insane population of Europe is not collected in specially built and regulated asylums, but scattered in most unsuitable places, in hospital wards, workhouses, indeed not seldom in penal institutions?

(c) What, we may ask, if we would be honest, are the so-called model asylums of modern times, but citadel-like barracks, or prisonhouses, which, alas! the public regard with amazement, and erroneously describe in the manner we have done in the first part of this essay?

(d) Who will deny that every country in Europe has a very insufficient number of asylums to meet the wants of the present time, of which, with reference to the foregoing query (b), the new buildings in course of erection, and the enlargement of old asylums, furnish the best evidence?

(e) Are not private asylums for the most part undertakings of non-professional persons?

(f) A general outcry is everywhere raised that the status of psychological physicians, especially in the larger asylums, is much too low,- but what will be said of the fact deduced from our own calculations, that in Europe there actually is, on an average, but one physician to every 300 lunatics?

(g) The miserable salaries which, in England, perhaps, alone excepted, the psychological physicians of Europe receive, the complete disregard on the part of the State of the performance of their self-sacrificing duty, the contempt of their colleagues who are engaged in other departments, are incontrovertible facts, to which there are few exceptions.

(h) It is likewise known, that the number of attendants is in general much too small, and that their characters and qualifications leave very much to be desired. Their salaries and future provision are lamentably insufficient. We have not yet arrived at the recognition of the necessity of schools for the education of attendants.

(i) With respect to the administrative arrangements of an asylum, to which so much praise is given by non-medical writers, we advance this plain proposition, that there are few asylums in Europe which, on this score, deserve unmixed commendation.

Few asylums are to be met with, the design and carrying out of the structure of which are not improper and unsuitable; the gardens and courts confined and dull (indeed, often none at all); the stairs and passages gloomy and inconvenient, frequently too, not lighted at all ; the day-rooms mostly of a cell-like aspect; and sometimes the corridors or the larger common rooms are made to do duty for them; decorations altogether wanting; comfort in most asylums, particu- 
larly in private ones, likewise deficient; much pretence and show without reality; and the same holds good of the diversions and amusements provided, for these are extremely seldom undertaken, and are mostly illusory.

Once a year a ball or a concert is given, to which high officials are invited; it is paraded pompously in the special and other journals, and is mostly a matter of pure ostentation.

We would except from this charge all those asylums where such amusements are frequent, and actually provided for the diversion of the patients-but the number of these is very small, and descriptions in such matters are less to be trusted than one's own eyes.

Billiard and music rooms are mostly found empty, and the requisite instruments damaged and useless ; the journals and books scattered about are old; and the different games undiscoverable; the library, when indeed there is such an apartment, is kept shut, and disused.

The dietary, with reference to the number, is often sufficient both in quality and quantity to satisfy all, but more frequently it is insufficient, and the bill of fare badly selected.

Uniformity prevails as the rule; often at the mid-day meal too little, and at supper too much food is given; all extras are great exceptions. Bread in general is too heavy ; beer and wine are in many places not attainable, in others, their quality is inferior.

Other great evils are : want of light and air, defective ventilation, ill-arranged and ill-placed passages, and very neglected closets ; completely unwarmed or very defectively warmed sleeping-rooms, which are to be so found almost everywhere, even in the severest winters; the want of window curtains, which indeed the darkness of the rooms and passages often render needless : too scantily and insufficiently furnished beds; a very negligent, or often entirely wanting supervision at night; and a regular night-watch within the building itself, and outside, not seldom absent altogether.

The moral treatment by occupation and amusements is often exceedingly defective, and in very many asylums entirely neglected. To appeal on this head to the proportion per cent., we learn, that of one hundred insane capable of being employed only one is actually engaged. Baths of every description, including those required for the purpose of cleanliness, are altogether wanting in many European asylums, or else are very insufficient and ill-contrived. Moreover, in many institutions neither baths nor the douche are often used. Vapour baths are scarcely ever met with.

The hour for retiring to rest is in many asylums absurdly early; in winter frequently between four and five o'clock, and in summer betwixt five and six. Moreover in most sleeping-rooms no protected light is provided.

A certain amount of cleanliness and so-called order is gencrally 
seen everywhere; still this has no merit, but is a natural duty. The staff of attendants is often inadequate and indifferent; and that the number of physicians and medical attendants is too small has indeed been already stated in a previous paragraph.

Visits made beyond the walls of the institution, indeed, are to be reckoned among rarities. The instruction of the insane, on which we lay no particular stress, although we estimate it as one means of diversion (of moral treatment), exists in very few asylums, and in these indeed in a very incomplete form.

The regulations for the government of the establishment are generally defective, and often a dead letter; medical and pathological anatomical studies and pursuits are also greatly neglected.

The central control over asylums and its value, of which we have hereafter to speak, when treating the second cardinal point of our essay, we shall not at present refer to.

Shall we picture in detail all those examples of mental disease, all those lunatics congregated together in general day-rooms, and specify their several conditions, by day and night, and their manifestations of depression or exaltation? or shall we speak of those among the 300,000 insane in Europe, whose whole life is a dreadful sacrifice to the system of coercion, shut in dark cells, or in restraint-chairs with camisoles, or confined by other apparatus, and who pine in restraint, until death delivers them from their torments? But of what use would all our efforts be, if-

4th. It is well known that the lunacy laws of Europe (with the exception perhaps of Holland), are throughout defective and insufficient ; in fact, in many countries, none yet exist, and quite recently a compilation of such laws is for the first time undertaken.

5th. As yet nothing has been done effectually anywhere in Europe, towards the clinical investigation of the treatment of insanity, and most of the universities seem to take a pride in the fact that they do not possess a chair of psychiatry. Surely these two last points in question are melancholy truths to be developed on all sides, and yet hitherto they have been only partially remedied in a few places!

If we now compare the conditions portrayed by us in the five propositions now examined, presenting the reverse of that bright picture drawn by the pencil of a non-professional visitor, all those false ideas and deltusions completely vanish, which the public still at this day entertain respecting the condition of asylums. That section of the public which obtains its opinion respecting the insanse, and their treatment from encyclopædias, romances, periodical and their feuilletons, is by no means small, and acquires, as a matter of course, perverted and fantastic notions, mostly difficult to combat 
and to rectify, for they become assimilated to the whole current of ideas.

Along with this, we must take into consideration that what such books and journals actually publish on such matters is, for the most part, the greatest trash.

We might have believed ourselves to be living in the middle ages, when we perused in all the political journals of Belgium the following notice, which we present word for word :-

"A hundred pensioners of the asylum of Ghent, on Monday last, took a walk out under the surveillance of their attendants. They marched in the greatest order and regularity to the sound of music, which kept them in step like old soldiers. On being conducted to a tavern, they partook of ham and a pint of beer to wash it down.

"One of the pensioners called out to a passer by,-we have got a thousand francs to spend. The time of departure having arrived, they re-arranged themselves in their ranks to return to their hospital. Some of them exercised surveillance over the others, and the fear of the control kept up perfect discipline.

"The attendants (frères), spoke to them as though they were children, and all were instinctively obedient to their voice. The one who had been posted as sentinel at the door of the tavern, not having received his share in the distribution of the good things, very rightly protested against the forgetfulness of which he was well nigh the victim. A substantial portion at once re-established the equilibrium of his feelings, and gave satisfaction to the complainant.

"They ate after the fashion of the Chinese or the Persians, knives and forks would be in their hands too dangerous weapons to entrust to their use. Fingers took their place, and the appetite suffered no abatement therefrom in any respect." 'L'Indépendence Belge,' 15th Avril, 1861.

This, however, is not the most extraordinary example we might adduce, for we could quote other illustrations more glaring.

One characteristic feature of our time is the universal cold indifference to the lot of the insane, and it is to this circumstance alone that we must look for the explanation, that to the majority of the public the present condition of the insane is not only unknown, but also indifferent. The opinion here pronounced is truly not to be found expressed in the debates of psychiatric meetings and societies, nor is it mentioned in the official reports and accounts of asylums, but nevertheless our observations are borne out by facts, and as we have before said, we hope we shall not be provoked to establish them by specific details.

Now with regard to the second part of our first cardinal question; viz., what gives rise to the false conceptions entertained by the public respecting the directors and superintendents of lunatic asylums, and

vOL. vII. 
how, in general, psychological physicians are estimated by them? We shall reply to it in the following paragraphs :

If the opinion relative to an object be false, we must, by a logical consequence, assume the reasoning with respect to the subject to have also been incorrect, inasmuch as the subject defines and governs the object.

To obtain a clear insight into this subject, we must be content to analyse the ever-recurring dreary chant, which the educated public have for years been repeating, respecting the courtesy, the gentlemanly and polished manners, the thorough knowledge of their profession, the self-sacrificing disinterestedness, \&c., \&c., attributed to the directors of lunatic asylums.

Sometimes individuals are likewise found, who utterly despise the idea of medical science as applied to the insane, and therefore regard with equal contempt both the directors and the physicians of asylums. This exemplifies one of the peculiarities of human nature, and bears out the well known saying, "tot capita, tot sensus."

We are proud to be able to substantiate in the most emphatic manner the optimist views held by the public generally, with regard to asylum physicians, and even consider it our duty to declare that the majority of them pursue their arduous and depressing round of duties with an amount of zeal, intelligence, and thorough devotion to their calling, which place them above all praise.

Psychological physicians must, indeed, in most instances, be content to find their only reward in the performance of their professional task, and in the study of their special subject; for, as we have already stated, the inducement of salaries, future provision, and honours, as usually awarded by the state, is entirely wanting in this peculiarly arduous branch of the profession. Even the educated classes, moreover, generally reward the medical care bestowed upon their lunatic relatives with oblivion and ingratitude, and professional colleagues in other departments are accustomed to shrug their shoulders in prophetic disparagement of the exertions of phrenopaths or psychologists. With respect to non-medical directors of lunatic asylums, we must speak in a very qualified manner, and frankly confess that, with the exception of a few worthy and experienced individuals, we have to deal, in general, with so many hotel keepers, good or bad, whose object it is to extract the largest profit from their respective establishments; hence they treat the insane as guests, charging them according to their several grades, and, as a matter of course; those who pay the best and cause the least inconvenience, are the longest kept.

Our experience has taught us that the State asylums of Europe generally possess the best and most conscientious superintendence, and here we would draw particular attention to Holland-the only country in Europe, which, possessing numerous good public insti- 
tutions for lunatics, is distinguished by the absence of private asylums; a circumstance which is the result of the labours of the world-renowned Schröder van der Kolk.

The professional duties of the psychiatric physician allow him, on the one hand, very little unoccupied time to mingle in general society, whilst on the other, the "phrenopath" courts retirement, and thus the public have few opportunities to know and to appreciate this class of physicians.

That the public at large, who regard with so much indifference the treatment of the insane, should extend this feeling to the practitioners and representatives of this specialty is therefore not surprising.

Even to the educated portion of the community, as a general thing, that asylum physician or director is the most welcome, who engages to receive a diseased relative at the lowest cost, is most profuse with brilliant promises, and raises the fewest impediments to admission. And not uncommonly, moreover, an unfavorable prognosis operates as a special recommendation. Sad as this statement may sound, it is no less a bitter truth.

We here speak only of what is the rule, for we cannot, from want of space, extend our remarks to particularise the exceptions, and for the same reason we must be silent respecting that class of the public which drags its disordered relatives from one asylum to another, never showing itself satisfied, nor of those persons who accept the morbid statements of the malcontent insane as evidence whereon they form their opinion of an asylum.

The quackish practice of many proprietors of private asylums, to envelope themselves and their establishments under the mysterious cloke of secrecy, induces a large proportion of the public to view lunatic asylums with some degree of superstition, and especially with mystery. Many still believe in the existence, behind those high securely guarding walls, gratings, and cells-of profound Eleusinian mysteries -in places where, alas! the Furies only rage, born to disease of Bacchus, Venus, and Pluto, or evoked by the unsearchable decree of Fate.

In many cases the public choose to assign the chief value to the moral treatment and discipline, and reserve theirgratitude for the system characterised by it; in other instances they attribute no value to such measures, and raise an outcry concerning the neglect of therapeutical treatment.

In the first case they are accustomed to say, "Now I have the right physician." In the second, "medicines must be given as in other diseases." And again, they say, "Nothing can be done ; when a man is mad, he remains so." The string of questions which has been a hundred times repeated to us and answered, is characteristic.

Question. How is my relative?-He is tranquil. I am pleased 
with his state. Question. What does he want, what does he require, what can I do to gratify him? Arswer. He needs nothing; we have supplied him with everything; he makes no request; it would only disturb him. Such is the general colloquy, and it satisfies, as a rule, half the friends of 300,000 insane in Europe. Every method of restraint is, with the public at large, a mysterious object to be wondered at, and educes no feelings of compassion or sympathy. These are significant facts which we cannot too strongly commend to general consideration.

Institutions managed by females are more valued and sought after by the male public than those conducted by persons of their own sex.

The burdens and collisions which are entailed upon the physicians and superintendents of asylums as a consequence of the authorised inspection by administrative boards, and which naturally quite escape the notice of the public, cannot, from the limited space at our disposal, be further alluded to.

This is the substance of what, in answering the first cardinal question of our essay, we have considered necessary to select from the multitude of ideas which the subject naturally suggests to the mind.

But in answering the second cardinal question, we have still some remarks to make.

It behoves us, in reference to that portion of the public which we designate as the "poor," and which has not enjoyed the advantages of instruction and education, to make some short observations relative to the above points.

The opinion entertained by the educated public exercises as a matter of course, the greatest influence on the latter class, and produces the same impressions under different forms and characters, which are modified moreover, as a natural consequence, by individual character. That in this class, superstition still exerts considerable influence, and that the devil, according to their interpretation, has much to do with insanity, is a wide-spread, popular belief in the south and north of Europe, and this is a circumstance not to be passed over in silence. Likewise, the delusion of a portion of the people that only poor persons become actually insane, but that the rich are kept shut up in asylums, on account of the commission of crimes and offences.

The modern Pinel-Esquirol reforms of asylums which at present constitute the general stagnation principle of our practice, enjoy among the uneducated classes, as is very intelligible, the same praise and wonderment they excite among their educated fellow men. The conductors of such asylums are uniformly looked upon by the uneducated as disinterested benefactors of mankind, whilst the psychiatric physician is regarded by them with indifference, and frequently taxed with quackery.

When personal risk, extreme poverty, or the injunction of 
magistrates, along with urgent need demand it, then only is it that the poor will, as a rule, entrust their insane relatives to an asylum. This often happens, indeed, from ignorance and want of judgment, yet on the other hand, it is also the consequence of a certain mistrust of such institutions.

It is conceivable that the rich, and those occupying a position in the world, on account of the many consequences which often disturb the family interests for many generations, and compromise their position, may strive to conceal their insane relatives; but with the poor this cause is entirely inoperative. The public, moreover, cannot be sufficiently warned against the concealment of those labouring under insanity. We know well that it is in mental disease pre-eminently necessary that the physician should be speedily, frequently, and perseveringly consulted, and his behests cheerfully and unhesitatingly obeyed.

Selfishness and bad advice and ignorance, are daily inflicting great mischief. Mankind in general, and in particular in poverty and in wealth, readily run into extremes, and hence it happens that both portions of the public, the educated and uneducated, either expect wonders from the physician, or reject his labours as worthless. Both the poor and rich put the question from time to time at an asylum, "Is my relative well or dead?" "verbum sapienti sat."

We close herewith our reply to the first cardinal question. Did Pinel reappear among us, he certainly would be greatly astonished, that we have stood still in the same field of practical knowledge which he bequeathed to us as a productive ground for progress. He would marvel that our generation held the same false ideas concerning our art and the institutions connected with it, as well as regarding their superintendents and physicians, as prevailed during his time But we must confess with shame, that we have remained at a stand-still since his death, until the present day, in the practice of our specialty ; nay, worse than at a stand-still, " Non progredi est regredi."

II. The question relative to the control and supervision of asylums has indeed been frequently enough discussed; but the results of these discussions, we must honestly admit, are very insignificant.

Moreover, official debates on this question are seldom published, because as state-affairs they are not considered eligible for publication. We do not as yet possess, as has been before remarked, any adequate code of lunacy in Europe, and it follows as a necessary consequence, that the supervision of lunatic asylums must also be imperfect. For it is evident, that one of the most important chapters in the law must be the fixing those definitions which shall invariably determine the sort and character of the control to be exercised.

If we look to the official reports of any country, which are prepared under the direction of different supreme commissions, committees, or boards of control and trustees, and periodically submitted to 
the ministers of state, and by them again laid before the representatives of the nation, we find - on a repeated and impartial examination of them-incontestable proof of that lamentable condition of things which we were compelled to delineate in the paragraphs 1 to 5 , occurring in our answer to the first cardinal question.

Without mentioning that, as a rule, in the preparation of such reports, the greatest consideration must be accorded to colleagues and others associated ; it is further a fact that not rarely they are the production of non-medical men, or at least are not prepared by special physicians ; and besides are published irregularly, and very tardily. A still greater evil is the circumstance, that such reports are in many countries not published at all, whilst in others they are addressed only to ministers and representatives, as scientific returns to be laid by among the archives of the country; and seldom does any public man venture an observation respecting them, and when it does so happen, the remarks are only of local interest, and scarcely ever touch upon any leading principle.

Before a subject of this kind is debated in a full assembly, and made the subject of legislation, more than ten years may glide by. Just as if this branch of knowledge did not deserve to rank among the most important questions that affect mankind.

We will now briefly discuss the questions :- $(a)$ By whom? (b) How often? (c) In what manner, and $(d)$ With what result are lunatic asylums inspected at the present day?

(a) Those who, in the several countries of Europe, inspect lunatic asylums, are usually very pains-taking and cultivated men, but very rarely physicians, and well nigh never asylum or psychiatric physicians.

Though they may be perfectly well qualified for the discharge of the administrative, and still more of the philanthropic portion of their duty, yet they stand in absolute need of the most weighty requirement, or of a practical fitness for the fulfilment of their office ; and this essential requisite is a knowledge of the pathology and the medical treatment of insanity. How, then, can the most important questions touching the good government of the insane be decided on by the supervisors, when these are not themselves physicians who make insanity a special study? And must we, for the future, as we do at the present day, allow the therapeutical details of asylum superintendence to remain without any control whatever?

It is an extraordinary circumstance that the directors and superior officers of charitable institutions, or indeed, of prisons, are frequently, at the same time, the principal inspectors of lunatic asylums. Asylums and prisons are too readily brought within the same category: a fact which affords striking evidence that the unconditional, indiscriminate sequestration of every lunatic leads to unreasoning uniformity or assimilation. 
The committee of management ordinarily consists of several government officials, or benevolent persons, a secretary, and now and then a physician, who, as before said, is scarcely ever an asylum physician, or one looked up to as an authority in this special department of medicine.

In many countries there is no higher superintending authority over asylums, except that supplied by members of the provincial sanitary boards. Many states again only delegate, as cases arise, some individual government official to undertake the particular control of the treatment of the insane.

With what want of design such arrangements are made can be further perceived from the fact, that in different countries of Europe lunatic asylums are included in the jurisdiction of the Minister of Justice, or in that of the Minister of Public Instruction, or again, in the department of the Interior; indeed, we know of one state where a short time ago the lunatic asylums were entrusted to the Minister of Commerce.

We must not forget to mention the several provincial, district, or county committees, in the composition of which likewise, as a rule, physicians are excluded.

These local committees, however, interpose the greatest obstacles to practical and speedy reform in the administration of asylum treatment. They are the drags to rational progress. What passion and weakness may not be found among their members! And hence arise those continual collisions between the professional superintendence and the administrative management of the institutions.

These committees commonly act only as a permanent opposition, paralyse the authority of the physician, make him appear as a very subordinate instrument, and often manifest themselves only as an element of disorder in the whole conduct of the institution. What asylum physician has not the saddest experience of this?

Divided authority is to the physician a source of great evil, whilst a subordinate position (as, for example, in private establishments belonging to non-medical men) annihilates his usefulness altogether.

We need devote several sheets to illustrate and exhaust this chapter, but as we fear lest our essay should become too voluminous, we shall pause here, and briefly discuss the other cardinal questions.

Besides, we believe enough has been already stated to demonstrate that, for the purpose of securing effective supervision this principle must be accepted, "that the position of the physician must be independent," and, as far as possible, officials and all the staff be always subordinate to him.

In our opinion, moreover, the control of lunatic asylums requires that the president of the committee should always be a member of the profession of authority in this specialty; and the majority of its 
members also, physicians, and as far as possible psychological physicians.

We would add, by way of further remark, how important are regulations for the psychiatric judicial department of our science, and leave our readers to deduce their own inferences.

(b) How often should lunatic asylums be visited? is a question easily answered.

As a rule, this is done only once a year, and frequently only once in every two or three years. In many countries, indeed, an inspection of an asylum is only called for and exercised when some scandal occurs. Commonly, also, such inspections were formerly notified in a private manner to the asylums concerned, or sometimes even officially announced. It is superfluous to trace the consequences of such proceedings more minutely.

In our opinion, lunatic asylums should be inspected at least once a month, and always without notice.

(c) The inspection of receptacles for the insane has been always conducted in a careless and superficial manner. The building is walked through, the store-rooms surveyed, some few patients or attendants spoken to, and then the inspector's room is re-entered, and after a shorter or longer talk with the officers of the institution and the physician, and after entering their names in the inspectionbook, after a few hours thus spent in the asylum the inspectors quit it with.a full conviction that they have sufficiently discharged their duty.

In our opinion, an inspection consists of two parts,-the one concerning the administrative, the other respecting the medical details; and to the latter we assign considerable importance.

But how is a commision to examine the insane and the history of their disorder, as well as the diagnostic, prognostic, and therapeutic entries in the case-books, when, as the rule, no psychiatric physician is found among its members? The consequence is, this most important part of the economy of the institution entirely escapes inspection. To arrive at any results on such points, certainly not a few hours in every year, but several days in every month can alone suffice. For these frequent inspections the staff of inspectors ought to be proportionately constructed, organized, regulated and paid. How necessary such inspections are for private asylums belonging to non-medical men, would very quickly be proved by their results. And we could produce illustrations of a recent date, which would confirm, in the strongest manner, the proposition advanced.

(d) The remarks on the question treated in section $c$, show clearly that the consequences of such inspections can generaily only be of a negative character. The results of such inspections are conveyed in the official reports of inspectors. And we must wonder in fact, at the indulgence and indolence of those gentlemen to whom such 
reports can be addressed. Confusedly put together, they contain praise and blame distributed pell-mell, and very seldom any positive suggestions of improvements. Year after year complaints are made respecting local and district difficulties, but the grumblers have not the sense, ordo not take the trouble, to solve the difficulties or to annihilate them. With measures for improved organization they scarcely ever deal, and pure medical questions are almost entirely ignored. And it is the fact that the editor of the reports is usually the secretary of the commission, and always, indeed, a non-medical man.

If we are desired to cite some good reports by way of models, we may be allowed to call attention to those of the Dutch asylums, and especially to the periodical returns of the present chief-physician of the Belgium Asylum at Gheel, Dr. Bulckens.

At the close of the answer to our second carlinal question, we have proved the correctness of the assertion with which we started, respecting the supervision and control of lunatic asylums, that a radical reform is exceedingly wanted.

III. We firmly entertain the opinion that physicians alone should be permitted to establish lunatic asylums. If we hold that the administrative department is the only ruling power in the management of such institutions, as it is now, alas! the custom of the day to think, those great evils which we have sought to depict in discussing the fifth point of the first cardinal question, must necessarily arise. Nothing can be more absurd or erroneous than the granting of licences for the erection of lunatic asylums, as they might be given for the opening of hotels or boarding-houses, to which establishments, after all, a house-surgeon is not unfrequently attached.

Monetary speculation on the misfortunes of others is a pitiable employment, and, as a rule, private lunatic asylums, established by non-medical men, are nothing else than investments of this kind.

Only asylum physicians who have for a considerable time practised in other, and particularly in public asylums, and who have thereby acquired considerable experience and skill, should receive as a reward for past, and an encouragement to future exertion, and as a distinction and means of provision, the privilege of a licence to establish an asylum for the wealthier classes. To this it may be objected that a certain capital is required, which asylum physicians generally have not at their disposal.

We reply to this objection that, very frequently, asylum physicians are in a position easily to obtain advances of capital for such generally profitable and privileged undertakings.

The heads of such institutions must be familiar with the treatment of insanity ; that is, they must be physicians-experts, if they are to be qualified for their duties. How then can such privileges be rightly conceded to non-medical men, or, indeed, to women? Is it not complete nonsense? And it is with great justice that in England protests, especially against the latter abuse, have been urged. 
We must not be supposed in any degree here to animadvert against the " patronal or family care of the insane," under the supervision of an asylum physician, of which we have to speak, in discussing the fifth cardinal question. Though a lunatic asylum established by a nonmedical man always has a permanent inspecting or house physician, it must be borne in mind that the relative position of this officer is always one of dependence on the director of the establishment. Again, it is very seldom that the physician is an alienist physician. Often, too, he does not live in the asylum, but is sent for as occasion requires. Under these and similar circumstances, the proceedings of non-professional directors and their attendants may be readily imagined. Official control, which supplies the only counterpoise in such matters, we have already shown to be extremely inadequate and impotent. It should therefore be established in the lunacy laws, as a principle, that none but physicians specially engaged in lunacy practice, and medical men who have made it their particular study, shall be allowed the privilege to establish lunatic asylums.

This should be the primary condition for such a privilege, the others would be guaranteed by the oath by which every physician binds himself to the performance of the general duties of his office.

Special guarantees, which this exceptional position require, must likewise be laid down in the lunacy laws. There is no fear of neglect in the administrative details, for these a practical psychological physician can soon learn. It is self-evident that the chief control or inspection by commissioners of asylums, conducted by psychological physicians must not be abolished, but be completely preserved in every point. This comprises, in a word, all we have to say in reply to the question before us.

We have intentionally avoided to discuss the reasons in detail which are adducible against the administration of lunatic asylums by non-medical persons, that we might not have continually to give examples of scandals, and illustrations of the evils prevalent in such institutions ; and I trust the impartial reader will give me credit for this.

IV. The reply to the foregoing third cardinal question, solves this present one by enabling us to give a categorical negative.

If non-medical persons should not, as a general rule, be entrusted with the management of lunatic asylums, this conclusion holds good in a special degree, with respect to religious corporations of either sex.

Let it not be overlooked that one-thirtieth part of the insane population of Europe is afflicted with religious madness. And another very important element in this matter is, that the clergy, and especially catholic priests, monks, and lay-brethren, are wanting in the most essential qualities requisite for a proper treatment of persons of unsound mind. 
- Is not a perfect acquaintance with people of all conditions from the palace to the hovel, a thorough practical conception of human existence and human motives in fortune and misfortune, in joy and sorrow, a condition for the right understanding and treatment of the insane? And need not a man have a family of his own, and live a social existence, in order to comprehend the multiform events occurring in families, and to be able to arrive at a correct opimion?

But these and many other matters are not to be learnt in the solitude of the cloister, but rather in the great places of human concourse, which the member of a religious order is compelled by his vocation to avoid.

Monastic discipline, pedantry, uniformity, lazy quietude, penuriousness, severity, moroseness, and silence, or in one word, perverted and impracticable ideas and performance, are found to be rife in most lunatic asylums conducted by religious fraternities. Long-continued religious exercises are actually expected to supply the place of medical treatment! Restraint is cherished, and flourishes in barbarous completeness, and all those evils prevail which have been pointed out in private asylums belonging to non-medical men.

The same objections apply to the servants belonging to religious houses of both sexes.

Whilst acknowledging the devotion with which these services are sometimes performed, we cannot admit that those gratifying practical results are attained which might be anticipated from them.

A certain degree of cleanliness and order generally found in institutions of this description, imposes upon the inspectors, who are accustomed to consider the fulfilling of a requirement, which though important, is only a necessary and general sanitary condition of every hospital, as the one thing needful. Indeed, we must here expressly allude to this circumstance as an oft-repeated vulgar error. In our opinion, religious corporations ought to be declared incapacitated to undertake the management and custody of the insane, in a special clause in the lunacy act, and thus be debarred from the management of lunatic asylums.

The only exception admissible to such restrictions would be where such corporations engaged in the systematic study of medicine, with the particular object of serving in hospitals, as for example, the corporation of serving-brothers in Austria.

V. By "patronal or family régime," we mean that kind of attention to the insane which is, in principle, wanting in asylum-life, for which family guardianship and care under the supervision and management of a psychological physician is substituted.

Such a method of treatment has hitherto unfortunately only been carried into practice on a large scale, at one spot in the world, namely, in the district of Gheel, in Belgium.

It still remains a duty in this century to create a Nazareth for the 
curing of the insane from this Bethlehem, for their care and treatment.

The eagerness with which this question has latterly been seized upon, augurs good. We have in other places (see the essay in the May and August numbers, 1860, of the Brussels 'Journal de MIédicine,' entitled “Gheel et ces Adversaires ;" also "L'indifférence de notre siècle pour l'infortune des Aliénés," and lastly, the 'Psychological Journal,' July, 1861) treated of Gheel, and the system there pursued, and we reserve for a systematic work the discussion of our views on this subject in general; we shall, therefore, as it does not concern our last cardinal question, say nothing in this place upon Gheel and the patronal system. Gheel is, as a rule, called a colony of insane, but in place of this, we substitute the term, proposed by Dr. Bulckens, the chief physician of Gheel, of "patronal or familylike asylum ;" and for the system pursued, the expression "patronal or family-like régime."

Dr. Bulckens makes use in his last report for 1860 , just published, of the terms "Patronal asylum," and "Family-like régime." Prof. Parigot calls the system "L'air libre et la vie de famille," or as it may be expressed in English, "Free air."

In England, the so-called system of cottage asylums and cottagetreatment, depends on the same principle. Lastly, we would reckon in the same category, if it were otherwise understood and carried out, and were subjected to reform, the arrangement alluded to in the reports of the "Select Committee on Lunatics," under the head of "lunatics with friends."

It is quite inmaterial which expression is employed, if only the principle is sufficiently enforced. But at the same time, mic retain the phrase "family-like régime" as most correct and convenient.

According to this, the wealthier classes of the insane should be brought together and taken charge of, in families-as a matter of course in others than their own, and this plan of providing for the care of the insane should, in our opinion, be established by law as the rule.

We have repeatedly added, in connection with this method of managenent, the clause "under the supervision and direction of a psychological physician." And this we desire not to let pass unnoticed.

As an avowed enemy to the indiscriminate sequestration of the insane, and upholding non-restraint in its widest signification, we feel called upon in the case of all those insane, where the cost of their care and treatment is of no moment, to advocate for them the "family régime."

All that can be generally urged respecting the disadvantages and evils of asylum-life, and of the benefits and successful results of family treatment, finds its application here. But as we consider 
these matters to be acknowledged, we will not now repeat them, but put forth the single question :-Why should not the law secure for the wealthy insane the most approved plan for their cure and attendance?

We avoid reverting to the general indifference to the lot of the insane ; nor will we mention the influence of family intrigues and their frequent sad consequences. As soon as it is once demonstrated that "family management" is the best system for the insane, the law should say, "sic jubeo," wherever the question of " posse" does not interpose.

This form of disorder cannot be compared with any other, for here it is the individual will, or the self consciousness that is paralysed, and the protection of the law is needed.

Family care must prevail as the rule, established by law, and extended to all who, having the means necessary to afford it, and the ability to remunerate professional attendants, are considered fit subjects for it in a judicial and scientific point of view. We are fully acquainted with the difficulties involved in the practical carrying out of this proposition; but the courage to attempt at least to overcome them, ought not to be wanting.

As the "family régime" can only spread and flourish under the management and treatment of a psychological physician, it is selfevident that it must be the chief concern of the physician to select for each patient a family suited to his station and the character of his malady, and at his first entrance to give effective assistance in the management and care of his patient.

Extreme and impracticable as this may sound, at the present time, it would in course of time come to be regarded as the natural course, if it were only earnestly pursued. It is certainly more convenient to call at the very first and nearest asylum in one's way, and there for a certain sum, to be freed from a lunatic relative.

In illustration of this method, the reader may peruse again the first five points of our first cardinal question.

We need scarcely explain that we do not intend to recognise as "family treatment" that method of hiding away rich lunatics, who are kept in distant places, in houses where they receive no aid from a psychological physician, in such a secret manner that they may be removed from public observation. Like Conolly, we denounce such deeds of barbarian ignorance. These are among the abuses we would wish to see abolished by the law.

Nevertheless, the "family régime" should be made the system of treatment, not only for the wealthier, but for all classes of society, without exception. We, therefore, do combat with the lunatic asylums of the present day, and advocate the "family régime" with all its consequences.

But all these propositions are, as before said, intimately connected 
with the radical reform of the practical part of our science. They should be discussed repeatedly. We need to speak out often, and at greater length, than we have been able to do here.

We have fearlessly ventured to portray in unvarnished truth, and with the responsibility of being held to our words, five of the weightiest questions of administrative psychiatry; questions the successful solution of which must exercise a powerful influence upon the therapeutics of insanity. May we not be misunderstood!

Is it desirable to advance in the practical treatment of the insane? for what does it profit mankind to make daily progress in theoretical knowledge, to multiply handbooks of psychiatry like mushrooms, to swell our special journals with extensive theoretical observations of all sorts, but at the same time to leave the practical part of phrenopathics, including the administrative portion, in a state of lamentable stagnation; while we reject every measure of true reform, and still vainly hold on to the rotten cable of "Routine?"

"Coupons le cable ; il est temps."

The Scientific Place and Principles of Medical Psychology. By J. Stevesson Bushnan, M.D.; Fellow of the Royal College of Physicians of Edinburgh; late Senior Physician to the Metropolitan Free Hospital ; Resident Proprietor of Laverstock House Asylum, near Salisbury.

Upos a recent occasion we took some pains to review the various significations in which the word "psychology" has been of late employed. We found that among some writers the use of this word had absolutely run wild. We pointed out that the word had not been . very long established in the language of science, and that its significance, even at present, admitted of some latitude. We expressed our opinion that the most warrantable use of the word is to signify the phenomenology of the human mind, including - l, the phenomena of knowledge ; 2, the phenomena of feeling; and 3, the phenomena of effort; but that it seemed still possible to give an extension to its meaning, so that it should include the psychology of man in the sense just indicated, or anthropo-psychology, and the psychology of the dumb creation, or eneo-psychology. If such an arrangement as this were adopted, it would nearly correspond with that which may be termed metaphysical psychology. The epithet metaphysical, as here applied to psychology, is not to be regarded as tautological or superfluous, 

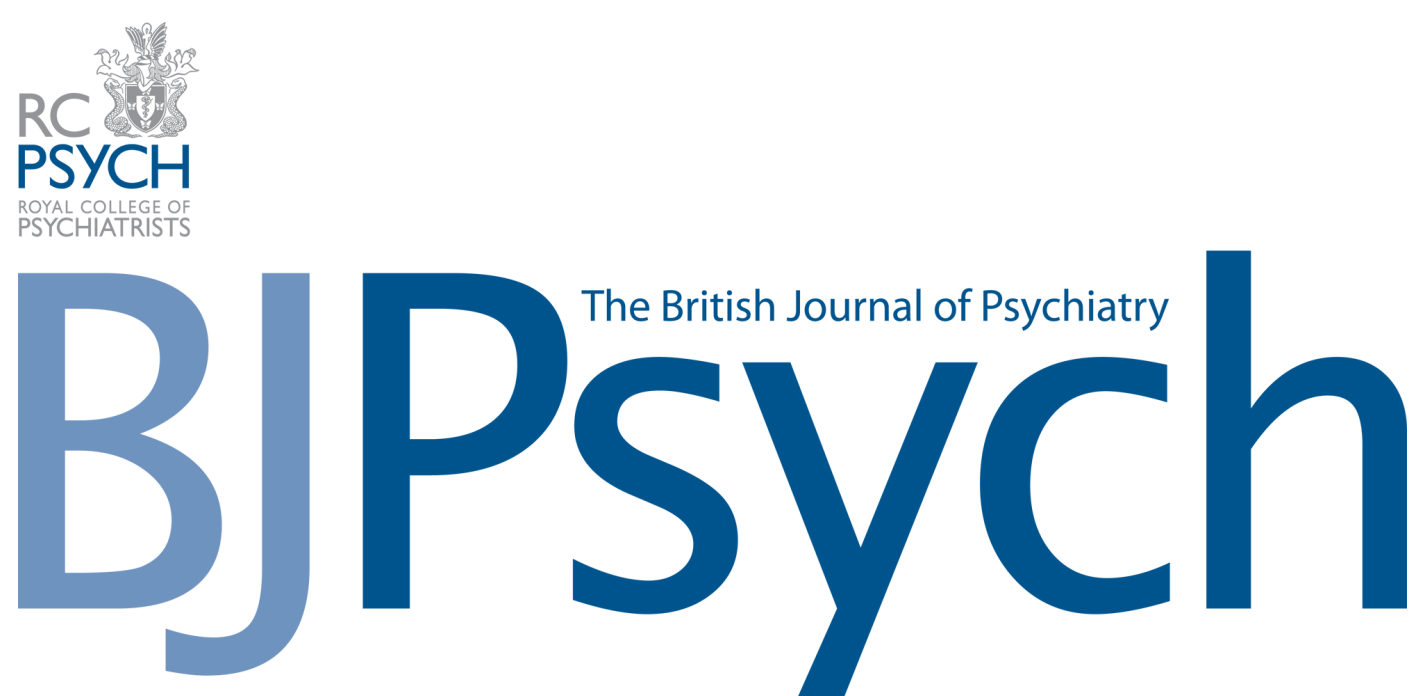

\section{Five Cardinal Questions on Administrative Psychiatry \\ J. Mundy}

BJP 1861, 7:343-370.

Access the most recent version at DOI: 10.1192/bjp.7.39.343

\begin{tabular}{cl}
\hline References & $\begin{array}{c}\text { This article cites } 0 \text { articles, } 0 \text { of which you can access for free at: } \\
\text { http://bjp.rcpsych.org/content/7/39/343.citation\#BIBL }\end{array}$ \\
$\begin{array}{c}\text { Reprints/ } \\
\text { permissions }\end{array}$ & $\begin{array}{l}\text { To obtain reprints or permission to reproduce material from this paper, please write } \\
\text { to permissions@rcpsych.ac.uk }\end{array}$ \\
$\begin{array}{c}\text { You can respond } \\
\text { to this article at } \\
\text { Downloaded } \\
\text { from }\end{array}$ & $\begin{array}{c}\text { /letters/submit/bjprcpsych;7/39/343 } \\
\text { Published by The Royal College of Psychiatrists }\end{array}$ \\
\hline
\end{tabular}

To subscribe to The British Journal of Psychiatry go to: http://bjp.rcpsych.org/site/subscriptions/ 